\title{
Epidural anesthesia for laparoscopic bariatric surgery: a case report
}

\author{
Wei-Chun Hung, Wei-Hung Chen, Yu-Hsuan Shih and Kuo-Chuan Hung*
}

\begin{abstract}
Background: Rapid and uneventful postoperative recovery following general anesthesia in morbidly obese patients undergoing bariatric surgery may offer challenges to anesthesiologists. With improved surgical techniques and shorter pneumoperitoneum, regional anesthesia may be considered for this laparoscopic procedure in selected cases.

Case description: The first patient was a 60-year-old male (body mass index: $39 \mathrm{~kg} / \mathrm{m}^{2}$ ) who was scheduled for laparoscopic sleeve gastrectomy. The second patient was a 46 -year-old female (body mass index: $47 \mathrm{~kg} / \mathrm{m}^{2}$ ) who was scheduled for laparoscopic gastric bypass. After standard intraoperative monitoring was applied, epidural anesthesia was performed at thoracic level T9-T10. Surgical technique modification included insufflation of $\mathrm{CO}_{2}$ at a low flow rate and avoidance of orogastric tube use. During the procedure, both patients breathed spontaneously without difficulty. One hypotension episode occurred and was successfully treated with a 12-mg bolus of ephedrine in case 1. Shoulder pain occurred intraoperatively in case 2 and was successfully treated with a $50-\mu \mathrm{g}$ bolus of fentanyl. Postoperatively, 2 mg epidural morphine was administered for postoperative analgesia. Both patients were satisfied with the anesthesia technique and was discharged uneventfully.
\end{abstract}

Discussion and evaluation: This anesthetic technique may maintain pre-operative respiratory function, increase alertness, and reduce the use of rescue analgesics, which is crucial for optimal outcomes in morbidly obese patients. Conversion of epidural anesthesia to general anesthesia may be required if patients can not tolerate the laparoscopic procedure (e.g. intolerable shoulder pain) or the increased respiratory rate during pneumoperitoneum leading to difficulty in performing laparoscopic surgery. Further studies are needed to elucidate this issue.

Conclusions: General anesthesia is widely used for laparoscopic bariatric surgery, but epidural anesthesia may be a viable alternative to general anesthesia in selected cases. Further prospective studies may be required to elucidate the relative advantages and disadvantages of epidural anesthesia in this surgical population.

Keywords: Epidural anesthesia, Laparoscopic bariatric surgery, Obesity

\section{Background}

Bariatric surgery, the only proven, effective, and durable treatment for morbidly obese patients (Brolin 2002), is commonly performed under general anesthesia with volatile anesthetics and neuromuscular blockade. However, general anesthesia with neuromuscular blockade increases upper airway collapse risk, pulmonary atelectasis, and postoperative pulmonary complications in this population (Pelosi et al. 1997). Acute respiratory failure, if occurs after bariatric surgery, may significantly

*Correspondence: ed102605@gmail.com

Department of Anesthesiology, E-DA Hospital, I-Shou University, 1, E-Da

Road, Jiau-shu Tsuen, Yan-Chau Shiang, Kaohsiung 824, Taiwan, ROC increase in-hospital mortality (Masoomi et al. 2013). We report two case of successful laparoscopic bariatric surgery under epidural anesthesia. With improved surgical techniques and shorter pneumoperitoneum, regional anesthesia may be considered as be a viable alternative to general anesthesia in selected cases.

\section{Case report}

The first patient was a 60-year-old male (weight: $115 \mathrm{~kg}$; height: $172 \mathrm{~cm}$; body mass index: $39 \mathrm{~kg} / \mathrm{m}^{2}$ ) who was scheduled for laparoscopic sleeve gastrectomy. His past history included tobacco-related chronic obstructive pulmonary disease (COPD) and asthma. Preoperative

\section{Springer}


pulmonary function tests revealed severe obstructive impairment, with forced vital capacity (FVC) $1.29 \mathrm{~L}$, one-second forced expiratory volume (FEV1) $0.76 \mathrm{~L}$, and FEV1/FVC 59\%. The second patient was a 46-year-old female (weight: $115 \mathrm{~kg}$; height: $157 \mathrm{~cm}$; body mass index of $47 \mathrm{~kg} / \mathrm{m}^{2}$ ) who was scheduled for laparoscopic gastric bypass. Her past history included diabetes mellitus, hypertension, and obstructive sleep apnea. Both patients had an ASA physical status 3 and physical examination was unremarkable. The airway, assessed with the patients in the sitting position, was judged to be Mallampati class I-II.

Both patients were scheduled for laparoscopic bariatric surgery because of failing conservative weight loss measures. The operative criteria were based on the Asia-Pacific guidelines for bariatric surgery, i.e. body mass index $\geqq 32 \mathrm{~kg} / \mathrm{m}^{2}$ in the presence of comorbidities and body mass index $\geqq 37 \mathrm{~kg} / \mathrm{m}^{2}$ with or without comorbidities. At the preoperative visit, both patients opted for epidural anesthesia after a detailed explanation regarding postoperative pulmonary complication risks. Epidural anesthesia and the possibility of intraoperative conversion to general anesthesia were explained.

Standard intraoperative monitoring included electrocardiography, noninvasive blood pressure, and pulse oximetry. After obtaining baseline vital signs, oxygen $(6 \mathrm{~L} / \mathrm{min})$ was commenced through a face mask. Both patients received ketorolac $30 \mathrm{mg}$ and meperidine $30 \mathrm{mg}$ as an analgesic premedication to relieve procedural discomfort. Before epidural anesthesia, they received Ringer's lactate solution $(500 \mathrm{ml})$. With both patients at the right lateral decubitus position, an 18-gauge TuohyHuber needle was introduced at the T9/T10 intervertebral space using the paramedian approach under full aseptic precautions. After "loss of resistance" to air was identified, a 20-gauge epidural catheter was threaded into place. The tip of the catheter was advanced $4-6 \mathrm{~cm}$ cephalad beyond the needle tip. After the catheter was taped to the patient's back, they were turned to the supine position. Thigh-length antiembolic stockings and sequential pneumatic compression devices were placed on both lower extremities for venous thromboembolism prophylaxis. Urine catheter was not inserted.

After intravascular/intrathecal injection was excluded by injecting a $3-\mathrm{ml}$ test dose of $2 \%$ lidocaine and epinephrine (1: 200,000), an intermittent bolus of $0.5 \%$ bupivacaine and $5 \mu \mathrm{g} / \mathrm{ml}$ fentanyl was injected to obtain segmental sensory block (pinprick) till the fourth thoracic dermatomes. The laparoscopic bariatric surgery was performed by an experienced surgeon, who performed 250-300 cases of laparoscopic bariatric surgery per year. Pneumoperitoneum was established with carbon dioxide at an intra-abdominal pressure of $13 \mathrm{mmHg}$.
To avoid vasovagal reflex and shoulder pain, the carbon dioxide was insufflated at a low flow rate $(2 \mathrm{~L} / \mathrm{min})$ (Yuksek et al. 2008). Then both patients was placed in reverse Trendelenburg position at $30^{\circ}-45^{\circ}$ angle. Calibrating orogastric tube was not used for gastric pouch formation. Laparoscopic bariatric surgery was performed according to the technique described before (Zachariah et al. 2013). No other intraoperative sedatives were administered.

In case 1, one episode of hypotension (systolic blood pressure $<90 \mathrm{mmHg}$ ) occurred after epidural anesthesia, and a 12-mg ephedrine bolus was intravenously administered. Afterward, his hemodynamic changes were minimal. The patient was alert and breathed spontaneously without difficulty. Intraoperatively, no shoulder pain or other discomfort was described. In case 2, shoulder pain occurred during penumoperitoneum and fentanyl $50 \mu \mathrm{g}$ was given intravenously to relieve the shoulder pain. No episode of hypotension or desaturation was observed during the procedure. The surgeon considered the abdominal relaxation was acceptable in both patients. However, increased respiratory rate in case 1 caused a slight disturbance during laparoscopic exploration. The procedure was completed without complications (operative time: $49 \mathrm{~min}$ ). In case 2, the laparoscopic procedure was completed without difficulty (operative time: $56 \mathrm{~min})$.

At the end of the operation, $2 \mathrm{mg}$ morphine plus $14 \mathrm{ml}$ normal saline was administered via the epidural catheter for postoperative analgesia in both patients. Then, the epidural catheter was removed. Both patients were able to move unassisted from the operating table to their bed after the operation. Postoperative recovery was uneventful. They did not experience nausea, vomiting, itching, urine retention, or respiratory depression. Rescue analgesics for pain were not required within $24 \mathrm{~h}$ postoperatively. Both patients were satisfactory with the anesthetic technique at the postoperative visit, and were discharged on postoperative day three.

\section{Discussion}

Obese patients often have poor pulmonary functional residual capacity and other spirometric parameters. As general anesthesia may cause increased intrapulmonary shunting and atelectasis, postoperative pulmonary complications are common in morbidly obese patients after laparoscopic bariatric surgery (Reinius et al. 2009). Respiratory failure in morbidly obese patients is associated with greater in-hospital mortality after bariatric surgery (Masoomi et al. 2013). Patients under regional anesthesia usually develop fewer pulmonary complications than those under general anesthesia (Pedersen et al. 1992); this is why we chose epidural anesthesia for this procedure. 
Carbon dioxide pneumoperitoneum may adversely affect intraoperative pulmonary mechanics (Nguyen et al. 2004). Therefore, our patient was at risk of intraoperative pulmonary distress. In a previous small feasibility study $(\mathrm{n}=23)$, Symeonidis et al. (2013), found that obese patients (mean body mass index: $36 \mathrm{~kg} / \mathrm{m}^{2}$ ) tolerate laparoscopic ventral hernia repair well without intraoperative pulmonary complications. Also, there are several reported cases of uneventful laparoscopic cholecystectomies that used regional anesthesia in patients with severe pulmonary disease (Kim et al. 2007; van Zundert et al. 2006; Pursnani et al. 1998). Pneumoperitoneum-induced respiratory distress did not occur in our patients. To maintain the reverse Trendelenburg position at $30^{\circ}-45^{\circ}$ angle during procedure and short duration of pneumoperitoneum may have also contributed to this.

There are several advantages to using regional anesthesia for laparoscopic bariatric surgery in both cases. First, preoperative pulmonary function parameters may be maintained throughout the surgery (Kim et al. 2007; van Zundert et al. 2006; Pursnani et al. 1998). In contrast, pulmonary function parameters may not return to preoperative levels until the seventh postoperative day in patients receiving general anesthesia (Nguyen et al. 2001). Secondly, both the laparoscopic procedure (Nguyen et al. 2002) and invasive tracheal intubation (Carron et al. 2012) may induce significant systemic stress response, which can have a potential detrimental effects in high comorbidity obese patients. Using epidural anesthesia for our patient helped avoid airway intervention and attenuated sympathetic responses caused by the surgical insult (Aono et al. 1998); this likely improved his postoperative outcomes and accelerated baseline function return. Finally, morbid obesity is generally concluded to be a risk factor for the development of perioperative deep venous thrombosis and pulmonary embolism (Wu and Barba 2000). The risk of deep venous thrombosis and pulmonary embolism is lower with epidural anesthesia than with general anesthesia (Rodgers et al. 2000).

Shoulder pain, caused by diaphragmatic irritation by insufflation gas, is common during laparoscopic surgery under regional anesthesia. A fentanyl bolus dose may relieve the shoulder pain; however, conversion of regional to general anesthesia may be necessary in some cases. In a prospective study $(n=180)$, the authors reported that the frequency of anesthetic conversions due to intolerable shoulder pain during laparoscopic cholecystectomy is 4.4\% (Bessa et al. 2012). Hypotension caused by neuraxial blockade is also common during laparoscopic surgeries (Lee et al. 2010), but it can be easily controlled with ephedrine, as in our case.

In our patients, $2 \mathrm{mg}$ epidural morphine was administered for postoperative analgesia, which may avoid the risk of ventilatory depression induced by intravenous opioid administration. Because of the absence of side effects, such as vertigo from general anesthesia and intravenous opioids, patients receiving epidural anesthesia and analgesia tend to ambulate earlier than patients receiving general anesthesia. Early ambulation may decrease the incidence of postoperative pulmonary complication in obese patients (Rawal et al. 1984).

In conscious patients, increased minute ventilation during laparoscopic procedures may lead to increased respiratory rate (Ciofolo et al. 1990), creating difficulty in performing the procedure. Although in our cases, the experienced surgeon considered the abdominal relaxation sufficient to continue, increased respiratory rate caused a slight disturbance during exploration in case 1 . The operative time was $49 \mathrm{~min}$ in this patient, which was favorable compared with previous surgeries by the same team. In their previous study, mean operative time was $60.63 \pm 27.37 \mathrm{~min}$ in patients under general anesthesia (Zachariah et al. 2013). This may imply that an experienced surgeon can handle a slightly increased respiratory rate. Other studies focusing on laparoscopic cholecystectomy also demonstrated no difference in operative time between regional and general anesthesia (Bessa et al. 2012). Further studies are needed to elucidate this issue.

There are some limitation in this report. First, difficulty in anesthetic technique may be encountered more frequently in obese patients, which may lead to a high failure rate when performing epidural anesthesia. Secondly, intraoperative conversion of epidural anesthesia to general anesthesia may be required if patients cannot tolerate the laparoscopic procedure (e.g. intolerable shoulder pain or prolonged surgical time). Finally, increased respiratory rate in awake patients during pneumoperitoneum may lead to difficulty in performing laparoscopic surgery. In this condition, conversion to general anesthesia is also required. These concern may discourage anesthesiologists and surgeons to perform this anesthetic technique for laparoscopic bariatric surgery. Further prospective studies with large sample size are required to clarify the indication and contraindication (relative advantages and disadvantages) of performing regional anesthesia for laparoscopic bariatric surgery.

\section{Conclusion}

This report reminds the anesthesiologists and surgeons that epidural anesthesia may be a viable alternative to general anesthesia for laparoscopic bariatric surgery in selected cases. This anesthetic technique may maintain pre-operative respiratory function, increase alertness, and reduce the use of rescue analgesics. A speedy return to baseline function is crucial for optimal outcomes in these patients. 


\section{Consent}

Both patients provided written consent for publication of this report.

\section{Abbreviations}

COPD: chronic obstructive pulmonary disease; FVC: forced vital capacity; FEV1: one-second forced expiratory volume.

\section{Authors' contributions}

Hung WC and Hung KC managed the patients clinically, gathered data and drafted the manuscript. Chen WH and Shih YH supervised the clinical practices and helped draft and revise the manuscript. All authors read and approved the final manuscript.

\section{Compliance with ethical guidelines}

\section{Competing interests}

The authors declare that they have no competing interests.

Received: 9 June 2015 Accepted: 10 July 2015

Published online: 17 July 2015

\section{References}

Aono H, Takeda A, Tarver SD, Goto H (1998) Stress responses in three different anesthetic techniques for carbon dioxide laparoscopic cholecystectomy. J Clin Anesth 10:546-550

Bessa SS, Katri KM, Abdel-Salam WN, El-Kayal el SA, TawfikTA (2012) Spinal versus general anesthesia for day-case laparoscopic cholecystectomy: a prospective randomized study. J Laparoendosc Adv Surg Tech A 22:550-555

Brolin RE (2002) Bariatric surgery and long-term control of morbid obesity. JAMA 288:2793-2796

Carron M, Veronese S, Gomiero W, Foletto M, Nitti D, Ori C et al (2012) Hemodynamic and hormonal stress responses to endotracheal tube and ProSeal Laryngeal Mask Airway ${ }^{\mathrm{TM}}$ for laparoscopic gastric banding. Anesthesiology 117:309-320

Ciofolo MJ, Clergue F, Seebacher J, Lefebvre G, Viars P (1990) Ventilatory effects of laparoscopy under epidural anesthesia. Anesth Analg 70:357-361

Kim YI, Lee JS, Jin HC, Chae WS, Kim SH (2007) Thoracic epidural anesthesia for laparoscopic cholecystectomy in an elderly patient with severely impaired pulmonary function tests. Acta Anaesthesiol Scand 51:1394-1396

Lee JH, Huh J, Kim DK, Gil JR, Min SW, Han SS (2010) Laparoscopic cholecystectomy under epidural anesthesia: a clinical feasibility study. Korean Anesthesiol 59:383-388
Masoomi H, Reavis KM, Smith BR, Kim H, Stamos MJ, Nguyen NT (2013) Risk factors for acute respiratory failure in bariatric surgery: data from the Nationwide Inpatient Sample, 2006-2008. Surg Obes Relat Dis 9:277-281 Nguyen NT, Lee SL, Goldman C, Fleming N, Arango A, McFall R et al (2001) Comparison of pulmonary function and postoperative pain after laparoscopic versus open gastric bypass: a randomized trial. J Am Coll Surg 192:469-476

Nguyen NT, Goldman CD, Ho HS, Gosselin RC, Singh A, Wolfe BM (2002) Systemic stress response after laparoscopic and open gastric bypass. J Am Coll Surg 194:557-566

Nguyen NT, Anderson JT, Budd M, Fleming NW, Ho HS, Jahr J et al (2004) Effects of pneumoperitoneum on intraoperative pulmonary mechanics and gas exchange during laparoscopic gastric bypass. Surg Endosc 18:64-71

Pedersen T, Viby-Mogensen J, Ringsted C (1992) Anaesthetic practice and postoperative pulmonary complications. Acta Anaesthesiol Scand 36:812-818

Pelosi P, Croci M, Ravagnan I, Cerisara M, Vicardi P, Lissoni A et al (1997) Respiratory system mechanics in sedated, paralyzed, morbidly obese patients. J Appl Physiol (1985) 82:811-818

Pursnani KG, Bazza Y, Calleja M, Mughal MM (1998) Laparoscopic cholecystectomy under epidural anesthesia in patients with chronic respiratory disease. Surg Endosc 12:1082-1084

Rawal N, Sjöstrand U, Christoffersson E, Dahlström B, Arvill A, Rydman H (1984) Comparison of intramuscular and epidural morphine for postoperative analgesia in the grossly obese: influence on postoperative ambulation and pulmonary function. Anesth Analg 63:583-592

Reinius H, Jonsson L, Gustafsson S, Sundbom M, Duvernoy O, Pelosi P et al (2009) Prevention of atelectasis in morbidly obese patients during general anesthesia and paralysis: a computerized tomography study. Anesthesiology 111:979-987

Rodgers A, Walker N, Schug S, McKee A, Kehlet H, van Zundert A et al (2000) Reduction of postoperative mortality and morbidity with epidural or spinal anaesthesia: results from overview of randomised trials. BMJ 321:1493

Symeonidis D, Baloyiannis I, Georgopoulou S, Koukoulis G, Athanasiou E, Tzovaras $G$ (2013) Laparoscopic ventral hernia repair in obese patients under spinal anesthesia. Int J Surg 11:926-929

van Zundert AA, Stultiens G, Jakimowicz JJ, van den Borne BE, van der Ham WG, Wildsmith JA (2006) Segmental spinal anaesthesia for cholecystectomy in a patient with severe lung disease. Br J Anaesth 96:464-466

Wu EC, Barba CA (2000) Current practices in the prophylaxis of venous throm boembolism in bariatric surgery. Obes Surg 10:7-13

Yuksek YN, Akat AZ, Gozalan U, Daglar G, Pala Y, Canturk M et al (2008) Laparoscopic cholecystectomy under spinal anesthesia. Am J Surg 195:533-536

Zachariah SK, Chang PC, Ooi AS, Hsin MC, Kin Wat JY, Huang CK (2013) Laparoscopic sleeve gastrectomy for morbid obesity: 5 years experience from an Asian center of excellence. Obes Surg 23:939-946

\section{Submit your manuscript to a SpringerOpen ${ }^{\circ}$ journal and benefit from:}

- Convenient online submission

- Rigorous peer review

- Immediate publication on acceptance

- Open access: articles freely available online

- High visibility within the field

- Retaining the copyright to your article

Submit your next manuscript at $>$ springeropen.com 